\title{
Implementasi Model Pembelajaran Mobile Learning Berbasis Android dalam Meningkatkan Prestasi Belajar Siswa Pada Pembelajaran Bahasa Inggris: Degrees of Comparison
}

\author{
Linda Setiawati ${ }^{1}$, Apip Purosad ${ }^{2}$, Deni Darmawan ${ }^{2}$ \\ ${ }^{1}$ Magister Teknologi Pendidikan Institu Pendidikan Indonesia, Bandung, Indonesia \\ ${ }^{2}$ Sekolah Pascasarjana Universitas Pendidikan Indonesia, Bandung, Indonesia \\ apiprosad@institutpendidikan.ac.id,ddarmawan@upi.edu
}

\begin{abstract}
Abstrak
Penelitian ini telah dilaksanakan selama dua bulan, yakni bulan April dan Mei 2019. Selama dua bulan itu yang dilakukan oleh peneliti adalah menyerahkan surat izin penelitian ke sekolah yang dituju, menentukan observer penelitian, menentukan sampel dan populasi, menyiapkan silabus, RPP, media model pembelajaran mobile learning yang berbasis android, instrumen soal, dan instrumen lembar jawaban. Kemudian dilakukan pretest untuk mengukur kemampuan siswa sebelum mengikuti proses pembelaaran baik aspek pengetahuan maupun aspek keterampilan, setelah itu dilaksanakan proses pembelajaran di mana kelas eksperimen diterapkan model pembelajaran mobile learning yang berbasis android sedang di kelas kontrol diterapkan model pembelajaran konvensional, dan pada pertemuan berikutnya dilaksanakan posttest di kelas eksperimen dan kelas kontrol dengan dengan menggunakan instrument soal aspek pengetahuan dan keterampilan yang sama. Dan dari hasil pretest dan posttest didapatkan hasil prestasi yang sangat berbeda antara kelas eksperimen dan kelas kontrol, di mana kelas eksperimen yang menggunakan model pembelajaran mobile learning yang berbasis android mendapatkan nilai yang lebih tinggi dibandingkan dengan kelas kontrol yang menggunakan model konvensional. Menelaah dari hasil tersebut peneliti dapat menyimpulkan bahwa model pembelajaran mobile learning yang berbasis android dapat meningkatkan prestasi belajar siswa pada pelajaran Bahasa Inggris dan model pebelajaran mobile learning direkomendasikan oleh peneliti sebagai model pembelajaran yang cocok digunakan dalam proses pembelajaran baik Bahasa Inggris maupun pelajaran lainnya.
\end{abstract}

\section{PENDAHULUAN}

Pengertian pendidikan Menurut UU No. 20 Tahun 2003: Pengertian pendidikan berdasarkan UU No.20 Tahun 2003 adalah usaha sadar dan terencana untuk mewujudkan suasana belajar dan proses pembelajaran agar pesertadidik secara aktif mengembangkan potensi dirinya untuk memiliki kekuatan spritual keagamaan, pengendalian diri, kepribadian, kecerdasan, akhlak mulia, serta keterampilan yang diperlukan dirinya, masyarakat, bangsa, dan negara.

Pengetian pendidikan Menurut Kamus Besar Bhs Indonesia (KBBI) : Pendidikan yakni satu sistem evaluasi untuk tiap-tiap individu untuk meraih pengetahuan serta pemahaman yang lebih tinggi tentang object spesifik serta khusus. Pengetahuan yang didapat secara resmi itu menyebabkan pada tiaptiap individu yakni mempunyai pola fikir, tingkah laku serta akhlak yang sesuai dengan pendidikan yang diperolehnya.

Teknologi pendidikan adalah teori dan praktek dalam desain pengembangan, pemanfaatan, pengelolaan, serta evaluasi proses dan sumber untuk belajar. Mereka yang setuju dengan istilah teknologi pendidikan mempunyai dua pendapat. Pertama, karena kata pembelajaran lebih sesuai untuk hal-hal yang berhubungan dengan sekolah atau lingkungan pendidikan. Mereka yang setuju dengan istilah teknologi pendidikan berdalih bahwa karena pembelajaran (instruction) dianggap oleh banyak orang sebagai bagian dari pendidikan, maka sebaiknya dipakai istilah yang memberikan cakupan yang lebih luas. 
Teknologi pendidikan tumbuh dari praktek pendidikan dan gerakan komunikasi audio visual. Teknologi pendidikan semula dilihat sebagai teknologi peralatan, yang berkaitan dengan penggunaan peralatan, media dan sarana untuk mencapai tujuan pendidikan atau mengajar dengan alat bantu audio-visual. Teknologi Pendidikan merupakan gabungan dari tiga aliran yang saling berkepentingan, yaitu media dalam pendidikan, psikologi pembelajaran dan pendekatan sistem dalam pembelajaran.

Multimedia pembelajaran merupakan salah satu komponen pembelajaran yang mempunyai peranan penting dalam kegiatan belajar mengajar. Pemanfaatan multimedia seharusnya merupakan bagian yang harus mendapat perhatian guru atau fasilitator perlu mempelajari bagaimana menetapkan media pembelajaran agar dapat mengefektifkan pencapaian tujuan pembelajaran dalam proses belajar mengajar. Multimedia interaktif adalah suatu multimedia yang dilengkapi dengan alat pengontrol yang dapat dioperasikan oleh pengguna, sehingga pengguna dapat memilih apa yang dikehendaki untuk proses selanjutnya. Peranan multimedia interaktif dalam bidang pendidikan semakin penting sejalan dengan pertumbuhan pengguna komputer.

Pemanfaatan teknologi informasi dan komunikasi di dalam dunia pendidikan terus berkembang dalam berbagai strategi dan pola, yang pada dasarnya dapat dikelompokan ke dalam sistem e-learning dan mobile learning. Media pembelajaran yang berbentuk $e$ learning memanfaatkan perangkat elektronik dan media digital. Mobile learning sebagai bentuk pembelajaran yang khusus memanfaatkan perangkat dan teknologi komunikasi bergerak. Faktor pendorong yang semakin memperluas kesempatan pengguanaan atau penerapan mobile learning yaitu tingkat perkembangan perangkat bergerak yang sangat tinggi, tingkat penggunaan yang relatif mudah dan harga perangkat yang semakin terjangkau dibanding perangkat personal komputer personal. Faktor pendorong tersebut menimbulkan kecenderungan baru dalam belajar.

Pada kenyataannya media pembelajaran masih sering terabaikan dengan berbagai alasan, antara lain: terbatasnya waktu untuk membuat persiapan mengajar, sulit mencari media yang tepat, tidak tersedianya biaya, dan lain-lain. Masalah tersebut juga terjadi pada mata pelajaran yang akan diteliti yaitu mata pelajaran Bahasa Inggris. Hal ini sebenarnya tidak perlu terjadi jika setiap guru atau fasilitator telah mempunyai pengetahuan dan keterampilan mengenai media pembelajaran.

Degrees of Comparison merupakan salah materi pembelajaran pada mata pelajaran Bahasa Inggris yang terdapat di SMK dalam Kompetensi Keahlian OTKP kelas X SMK semester II. Pada pelajaran ini siswa dituntut mengenal, memahami dan mampu menggunakan kata sifat dalam perbandingan baik dalam bahasa lisan maupun tulisan dan mampu mengaplikasikan ke dalam pengunaan Bahasa Inggris secara komunikatif.

Pengetahuan dasar yang harus difahami siswa dalam materi pelajaran Degrees of Comparison adalah kata Positive Adjective, Comparative Adjective, Superlative Adjective, Comparative Adjective + than, Comparative Adjective and Comparative Adjective, perubahan positive ke Comparative dan penggunaan Positive Adjective, Comparative Adjective, Superlative Adjective dalam kalimat lisan maupun tulisan. 
Gunahumas

Jurnal Kehumasan $\begin{array}{crlr}\text { Sampai } & \text { saat } & \text { ini } & \text { kegiatan } \\ \text { pembelajaran } & \text { di } & \text { kelas } & \text { hanya }\end{array}$ dilaksanakan secara ceramah dan diskusi, terlebih jika di sekolah kurang tersedianya sarana prasarana pendukung pembelajaran seperti perangkat komputer tetapi kegiatan pembelajaran masih monoton, terlihat dari kegiatan pembelajaran dengan hanya bergantung pada instruksi atau perintah guru.

Multimedia pembelajaran dalam mata pembelajaran Bahasa Inggris dengan menggunakan model mobile learning berbasis android diharapkan dapat memperlancar interaksi antara guru dengan siswa, sehingga kegiatan pembelajran lebih efektif dan efisien. Dengan proses pembelajaran yang jelas, menyenangkan dan menarik dapat meningkatkan pengetahuan materi pelajaran Bahasa Inggris Degrees of Comparison.

Pengajuan usulan penelitian ini dimulai dengan melihat masalah yang terjadi di tempat peneliti mengajar yaitu kelas X OTKP 1 dan X OTKP 2 SMKN 14 Garut. Berdasarkan pengamatan sementara di kelas X OTKP 1 dan $\mathrm{X}$ OTKP 2 SMKN 14 Garut, ditemukan permasalahan masih belum optimalnya penggunaan media pembelajaran. Para siswa menggunakan handphone android lebih memanfaatkan untuk mengunjungi sosial media seperti $B B M$, twitter, facebook, instagram, line whatsapp dan game daripada hal yang berkaitan dengan materi pelajaran, padahal alternatif media pembelajaran untuk meningkatkan pemahaman siswa terkait materi tertentu. Maraknya penggunaan handphone android untuk menarik motivasi siswa dalam belajar dan dapat menunjang ketercapaian pemahaman siswa. Salah satunya dengan menggunakan media pembelajaran mobile learning. Bedasarkan latar belakang penelitian tersebut di atas, maka peneliti mengambil judul "Implementasi Model Pembelajaran Mobile Learning Berbasis Android dalam Meningkatkan Prestasi Belajar Siswa pada Pembelajaran Bahasa Inggris: Degrees of Comparison (Penelitian kelas X OTKP 1 dam X OTKP 2 SMKN 14 Garut)".

\section{KAJIAN PUSTAKA, KAJIAN TEORITIS DAN KERANGKA BERPIKIR PENELITIAN}

\section{Kajian Pustaka}

\section{Teknologi Pendidikan}

Teknologi pendidikan menurut AECT (Association for Educational Communication and Technology) adalah suatu proses yang kompleks dan terpadu dengan melibatkan peralatan, ide, prosedur, orang dan organisasi untuk menganalisis permasalahan, menemukan problem solving, melakukan evaluasi serta mengelola pemecahan masalah yang berkaitan dengan semua aspek belajar manusia.

Teknologi pendidikan adalah kajian serta praktik yang dapat membantu proses belajar untuk meningkatkan kinerja dengan cara membuat, menggunakan dan mengelola segala proses dan sumber teknologi. Banyak yang menghubungkan antara istilah teknologi pendidikan dengan teori belajar dan pembelajaran. Perbedaan yang mendasar dari keduanya adalah teori belajar dan pembelajaran meliputi proses dan sistem dalam kegiatan belajar dan pembelajaran, sedangkan teknologi pendidikan adalah proses untuk mengembangkan kemampuan siswa.

\section{Mobile Learning}

Mobile learning adalah salah satu unsur pendukung dalam proses pendidikan dan pelatihan, dengan 
menggunakan media yang moblie, semacam PDA. Smart Phone, dan juga Mobile Phone. Kata Keegan, dalam mobile learning terdapat kenyamanan dalam pemanfaatan fungsi dan kemudahan media atau alat yang digunakan.

\section{Android}

Android merupakan sistem operasi yang dikembangkan untuk perangkat mobile yang berbasis linux seperti telepon pintar dan komputer tablet. Android merupakan OS mobile yang tumbuh di tengah $O S$ lainnya yang berkembang dewasa ini. OS lainnya seperti Windows Mobile, i-Phone OS, Symbian, dan masih banyak lagi yang lainnya yang menawarkan kekayaan isi dan keoptimalan berjalan di atas perangkat hardware.

\section{Degrees of Comparison}

Degrees of Comparison adalah bentuk adjective (kata sifat) atau adverb (kata keterangan) yang menyatakan perbandingan. Ada tiga degree of comparison, yaitu: positive, comparative, dan superlative degree.

\section{Kajian Teoritis}

\section{Pembelajaran}

Pembelajaran merupakan suatu proses perubahan, yaitu perubahan perilku sebagai hasil interaksi dengan lingkungan dalam memenuhi kebutuhan hidup. Pembelajaran menggambarkan suatu proses yang dinamis karena pada hakekatnya perilaku belajar diwujudkan dalam suatu proses yang dinamis dan bukan sesuatu yang diam atau fasif ( Surya, 2015:111).

\section{Teknologi Pendidikan}

Teknologi Pendidikan adalah aplikasi sistematik dan pengetahuan lain dalam rugas pendidikan "Systematic application of scientific or other organizer knowledge to practical task", ( Abdulhak dan Darmawan, 2013:106). Penggabungan antara teknologi pembelajaran, teknologi belajar, teknologi perkembangan, tekonlogi pengelolaan dan teknologi lainnya, dengan tujuan untuk keperluan dalam pemecahan masalah di dunia pendidikan

\section{Mobile Learning}

Mobile learning (m-learning) adalah suatu pendekatan pembelajaran yang melinatakan device (perangkat) bergeraka seperti telepin genggam, PDA, laptop dan tablet PC, di mana pembelajar dapat mengakses materi, arahan dan aplikasi yang berkaitan dengan pelajaran tanpa dibatasi oleh ruang dan waktu, di mana pun, kapan pun mereka berada (Darmawan 2015:15)

\section{Android}

Android merupakan generasi baru dalam perangkat mobile yang benar benar terbuka kepada para pengembang untuk melakukan pengembangan sesuai dengan apa yang diinginkan oleh para pengembang. Android merupakan open source, sehingga dapat secara bebas diperluas dan dikembangkan untuk menjadi lebih maju, (Safaat, 2012: 1).

\section{Degree of Comparison}

Degree of Comparison adalah bentuk adjective (kata sifat) atau adverb (kata keterangan) yang menyatakan perbandingan. Ada tiga degree of comparison, yaitu: positive, comparative, dan superlative degree.

\section{Kerangka Berpikir}

Berkaitan dengan fenomena masalah yang ditemui dalam pembelajaran Bahasa Inggris di kelas X OTKP 1 dan X OTKP 2 SMKN 14 Garut, yaitu: 
Gunahumas

Jurnal Kehumasan

1. Paradigma pendidikan/ pengajaran telah bergeser dari paradigma lama (teacher-oriented) ke paradigma baru (student-oriented dan integrated) yang dengan sendirinya memerlukan perubahan pola pendekatan pembelajaran, yang pada gilirannya menuntut perubahan-perubahan pada berbagai aspek pembelajaran, khususnya pada mata pembelajaran Bahasa Inggris pada Kompetensi Keahlian OTKP. Pada metode lama menggunakan pendekatan penguaasaan bidang ilmu dengan berorientasi pada isi (content) pembelajaran, sedangkan pembelajaran sekarang menekankan pada pengembangan daya kognisi, afeksi dan keterampilan. Guru tidak lagi sekedar memberi materi, namun lebih ditugasi sebagai fasilitator, motivator, dan dinamisator bagi perkembangan intelektual dan sosial siswa.

2. Media pembelajaran masih sering terabaikan dengan berbagai alasan, antara lain: terbatasnya waktu untuk membuat persiapan mengajar, sulit mencari media yang tepat, tidak tersedianya biaya, dan lain lain. Masalah tersebut juga terjadi pada mata pelajaran yang akan diteliti yaitu mata pelajaran Bahasa Inggris. Hal ini sebenarnya tidak perlu terjadi jika setiap guru/ fasilitator telah mempunyai pengetahuan dan keterampilan mengenai media pembelajaran.

Berdasarkan uraian tersebut, maka kerangka berpikir tersebut dapat diilutrasiakn dalam gambar berikut:

\section{Hipotesis}

Hipotesis adalah jawaban sementara tehadap suatu permasalahan penelitian. Adapaun hipotesis dalam penelitian ini adalah:

a. Dengan penggunaan mobile learning berbasis android akan dapat memanfaatkan smartphone / handphone yang dimiliki siswa secara maksimal pada proses pembelajaran

b. Dengan penggunaan mobile learning berbasis android akan dapat meningkatkan prestasi siswa pada pembelajaran Bahasa Inggris di kelas X OTKP 1 SMKN 14 Garut.

c. Dengan penggunaan mobile learning berbasis android akan dapat melihat perbedaan yang signifikan hasil prestasi belajar siswa antara kelas eksperimen dan kelas kontrol.

\section{METODE}

\section{Pendekatan dan Metode Penelitian}

\section{Pendekatan Kuantitatif}

Menurut Sugiyono (2016:14) pendekatan kuantitatif adalah pendekatan yang berlandaskan pada filsapat positivisme, digunakan untuk meneliti pada populasi atau sampel tertentu, teknik pengambilan sampel pada umumnya dilakukan secara random, pengumpulan data menggunakan instrumen penelitian, analisis data bersifat kuantitatif/statistik dengan tujuan untuk menguji hipotesis yang telah ditetapkan.

\section{Metode Eksperimen}

Penelitin ini menggunakan metode eksperimen, yaitu suatu penelitian yang berusaha mencari pengaruh variabel tertentu terhadap variabel lain dalam kondisi yang terkontrol secara ketat (Sugiyono, 2015 : 11). Sedang menurut 
Darmawan (2016 : 226 ), penelitian eksperimen (experimental research) adalah kegiatan penelitian yang bertujuan untuk menilai pengaruh suatu perlakuan/ tindakan/ treatment pendidikan terhadap tingkah laku siswa atau menguji hipotesis tentang ada tidaknya pengaruh tindakan itu bila dibandingkan dengan tindakan lain. Berdasarkan hal tersebut, maka tujuan umum penelitian eksperimen ini adalah untuk meneliti pengaruh dari suatu perlakuan tertentu terhadap gejala suatu kelompok tertentu dibanding dengan kelompok lain yang menggunakan perlakuan berbeda.

\section{Desain Penelitian}

Dalam penelitian ini, peneliti menggunakan Metode Eksperimen dengan bentuk desain eksperimen Quasi Eksperimental Design, sedangkan bentuk desain quasi eksperimen yang digunakan adalah Nonequivalent Groups Pretest-Postest Design. Desain ini sangat lajim dan berguna dalam penelitian pendidikan, karena sangat tidak mungkin untuk menempatkan subjek secara acak, Peneliti menggunakannya secara utuh, kelompok subjek yang telah ditentukan, memberi pretes, mengelola kondisi perlakuan pada satu kelompok, dan memberinya postes (Mc Millan dan Schumacher, $2001: 342$ ).

Tabel 1. Desain Penelitan Eksperimen Nonequivalent Groups Pretest-Postest Design.

\begin{tabular}{lccc}
\hline $\begin{array}{c}\text { Kelompo } \\
\mathrm{k}\end{array}$ & $\begin{array}{c}\text { Prete } \\
\text { st }\end{array}$ & $\begin{array}{c}\text { Perlaku } \\
\text { an }(\mathrm{X})\end{array}$ & $\begin{array}{c}\text { Postte } \\
\text { st }\end{array}$ \\
\hline $\begin{array}{l}\text { Eksperim } \\
\text { en }\end{array}$ & $\mathrm{O}$ & $\mathrm{X}$ & $\mathrm{O}$ \\
Kontrol & $\mathrm{O}$ & $\mathrm{O}$ \\
\hline \multicolumn{3}{c}{ Waktu } \\
\hline
\end{tabular}

\section{Populasi dan Sampel}

\section{Populasi Penelitian}

Populasi adalah keseluruhan subjek atau objek yang menjadi sasaran penelitian yang mempunyai karakteristik tertentu (Sundayana, 2016:15). Sedangkan Santoso (2016:4) memberi definisi populasi, adalah sebagai sekumpulan data yang mengidentifikasi suatu fenomena. Kemudian Santoso (2016 : 5) menjelaskan bahwa definisi populasi lebih tergantung pada kegunaan dan relevansi data yang dikumpulkan. Dalam penelitian ini yang dimaksud populasi siswa kelas X OTKP 1 dan X OTPK 2 SMKN 14 Garut sejumlah 65 orang (Kelas OTKP 1 sebanyak 30 orang dan Kelas OTKP 2 sebanyak 30 orang).

\section{Sampel Penelitian}

Sampel menurut Healey dalam Wahyudin (2013:2) suatu subjek yang dipilih secara teliti dari populasi tertentu. Sedangkan menurut Sundayana (2014:15) adalah sejumlah (tidak semua) hal yang diobservasi/diteliti yang relevan dengan masalah penelitian serta memiliki karakterisitk yang dimiliki populasi. Dalam menentukan sampel penelitian untuk memperoleh sampel yang baik, menurut Darmawan (2014) harus memenuhi syarat di antaranya:

a. Akurasi dan ketepatan, yaitu tingkat ketidakadaan bias atau kekeliruan

b. Presisi, yaitu memiliki tingkat presisi estimasi mendekati karakteristik populasi.

Adapun yang menjadi sampel dalam penelitian ini sebanyak dua kelas yaitu kelas $\mathrm{X}$ OTKP 1 sebagai kelas eksperimen sejumlah 30 siswa dan kelas $\mathrm{X}$ OTKP 2 sebagai kelas kontrol sebanyak 30. Pengambilan dan penentuan kelas dalam penelitian ditentukan berdasarkan kriteria rata-rata kemampuan hasil belajar siswa. Untuk kelas eksperimen adalah kelompok siswa dengan kemampuan hasil belajar rendah. Sedangkan kelas kontrol adalah 


\section{Gunahumas}

Jurnal Kehumasan

kelompok siswa dengan kemampuan sedang yang keterangannya dapat dilihat pada lampiran.

\section{Jenis dan Sumber Data Jenis Data}

Data ialah bahan mentah yang perlu diolah sehingga menghasilkan informasi atau keterangan yang menunjukkan fakta. Jenis data yang digunakan dalam penelitian ini bersifat kuantitaf dan kaulitatif karena data yang didapat merupakan hasil pretest dan post test, baik yang menggunakan maupun yang tidak menggunakan mobile learning, untuk aktivitas dan hasil belajar materi Degrees of Comparison kelas X OTKP 1 dan X OTKP 2 SMKN 14 Garut.

\section{Sumber Data}

Sumber data penelitian ini adalah sumber-sumber data yang diperlukan penelitian baik secara langsung maupun tidak langsung. Dalam penelitian ini menggunakan sumber data sebagai berikut:

\section{1) Data Primer}

Data primer merupakan data yang diperoleh langsung dari subjek yang berhubungan dengan objek penelitian. Data yang digunakan adalah data primer yang dikumpulkan dengan metode questioner dan tes yang diberikan langsung kepada ssiwa kelas X OTKP 1 dan X OTKP 2 SMKN 14 Garut.

\section{2) Data Sekunder}

Data sekunder adalah data yang diperoleh dari subjek yang tidak berhubungan langsung dengan objek penelitian tetapi sifatnya membantu dan memberikan informasi untuk bahan penelitian. Data sekunder dalam penelitian ini adalah jurnal, buku-buku, dokumen dan lain-lain.

\section{Instrumen Penelitian}

Instrumen yang digunakan dalam penelitian adalah berupa Tes bentuk atau tipe objektif. Tes bentuk atau tipe objektif, sangat cocok untuk menilai kemampuan yang menuntut proses mental yang tidak begitu tinggi, seperti mengingat, mengenal, pengertian, dan penerapan prinsip-prinsip (Arifin, 2014: 135). Sedangkan macam Tes bentuk atau tipe objektif yang akan digunakan sebagai alat pengukuran penilaian berupa Menjodohkan atau Matching yaitu terdiri atas kumpulan soal dan kumpulan jawaban yang keduanya dikumpulkan pada dua kolom yang berbeda, yaitu kolom sebelah kiri menunjukkan sekumpulan soal, dan sebelah kanan menunjukkan kumpulan jawaban. Jumlah pilihan jawaban dibuat lebih banyak dari pada jumlah soal. Bentuk soal menjodohkan sangat baik untuk mengukur kemampuan peserta didik dalam mengidentifikasi informasi berdasarkan hubungan yang sederhana dan kemampuan mengidentifikasi hubungan antara dua hal ( Arifin, 2014 : 144 ).

Sebelum soal ini digunakan terlebih dahulu diujicobakan dengan maksud untuk mengukur validitas, reliabilitas, indeks kesukaran dan daya pembedanya dengan tahapan pengukuran sebagai berikut :

\section{Validitas}

Validitas adalah suatu ukuran yang menunjukkan tingkat kevalidan atau kesahihan suatu instrumen. Dalam penelitian ini, uji coba instrumen penelitian atau uji validitas instrumen dilaksanakan di sekolah yang akan dijadikan tempat penelitian dengan mengambil kelas yang tidak dijadikan objek/sampel penelitian (Sundayana, 2016 :59). Adapun jumlah siswa yang akan dijadikan anggota populasi untuk 
uji validitas jumlahnya 30 siswa, hal ini sesuai dengan tulisan Sugiyono (2016:141) bahwa untuk uji validitas dapat dilakukan terhadap 30 orang anggota populasi. Dalam penelitian ini subjek atau responden yang akan dijadikan responden untuk uji validitas adalah sejumlah 30 siswa kelas X OTKP 1 SMKN 14 Garut.

Perhitungan validitas butir soal dilakukan dengan menggunakan rumus korelasi product moment Pearson ( Sundayana, $2016: 60)$ :

$$
r_{x y}=\frac{N \sum X Y-\left(\sum X\right)\left(\sum Y\right)}{\sqrt{\left\{N \sum X^{2}-(X)^{2}\right\}\left\{N \sum Y^{2}-\left(\sum Y\right)^{2}\right\}}}
$$

Untuk mengetahui apakah valid atau tidak, peneliti membandingkan antara $\mathrm{t}$ hitung dengan $t$ tabel, dengan ketentuan apabila $t$ hitung lebih besar dari pada $t$ tabel, atau apabila probabilitas (sig) lebih kecil dari pada 0,05, maka instrumen dikatakan valid dan sebaliknya (Rusman, 2015 : 40). Untuk mengetahui $\mathrm{t}$ tabel, dapat dilihat pada Tabel III Nilai-nilai $r$ Product Moment (Sugiyono, 2014 : 369), dimana untuk anggota sampel 30 orang dengan taraf signifikan 5,00 \% menunjukkan angka t tabel 0,361 .

Tabel 2. Klarifikasi Kriteria Koefisien Validitas

\begin{tabular}{cc}
\hline Koefisien & Kriterian \\
Korelasi & Validitas \\
\hline $0.80 \leq$ rxy $\leq 100$ & Sangat Tinggi \\
$0.60 \leq$ rxy $\leq 80$ & Tinggi \\
$0.40 \leq$ rxy $\leq 60$ & Cukup \\
$0.20 \leq$ rxy $\leq 40$ & Rendah \\
$0.00 \leq$ rxy $\leq 20$ & Sangat Rendah \\
\hline
\end{tabular}

\section{Reliabilitas}

Reliabilitas instrumen penelitian adalah suatu alat yang memberikan hasil yang tetap sama atau konsisten atau ajeg. Dalam menguji reliabilitas instrumen penelitian ini, peneliti menggunakan rumus Spearman-Brown karena soal tesnya termasuk bentuk atau tipe objektif (Sundayana, 2016 : 69). Adapun rumus Spearman-Brown seperti nampak dibawah ini (Sundayana, $2016: 70)$ :

$$
r \frac{1}{2}=\frac{n\left(\sum x 1 \times 2\right)-\left(\sum X 1\right)\left(\sum X 2\right)}{\sqrt{\left.\left[n \sum x_{1}^{2}\right)\right]}}
$$

Koefisien reliabilitas yang dihasilkan selanjutnya diinterpretasikan dengan menggunakan klasifikasi koefisien reliabilitas dari Guilford (Sundayana, 2016 : 70) sebagai berikut :

Tabel 3. Klarifikasi Koefisien Reliabilitas

\begin{tabular}{cc}
\hline Koefisien & Interpretasi \\
Reliabiltas $(r)$ & \\
\hline $0,00 \leq \mathrm{r}<$ & Sangat Rendah \\
0,20 & \\
$0,20 \leq \mathrm{r}<$ & Rendah \\
0,40 & \\
$0,40 \leq \mathrm{r}<$ & Sedang/Cukup \\
0,60 & \\
$0,60 \leq \mathrm{r}<$ & Tinggi \\
0,80 & \\
$0,80 \leq \mathrm{r} \leq$ & Sangat Tinggi \\
1,00 & \\
\hline
\end{tabular}

\section{Tingkat Kesukaran}

Tingkat kesukaran adalah keberadaan suatu butir soal apakah dipandang sukar, sedang, atau mudah dalam mengerjakannya (Sundayana, 2016:76) Untuk mengetahui tingkat kesukaran untuk soal tipe objektif, peneliti menggunakan rumus serta klasifikasi berdasar tulisan Sundayana (2016:76-77) :

$$
T K=\frac{J B_{A}+J B_{B}}{2 . J S A}
$$

Setelah dilakukan perhitungan mengenai tingkat kesukaran, maka peneliti sajikan pada tabel berikut: 
Gunahumas

Jurnal Kehumasan
p-ISSN: 2338-1507

Vol 3, No 2, 2020, 49-56
Tabel 4. Rekapitulasi Tingkat

Kesukaran Butir Soal Instrumen Penelitian

\begin{tabular}{ccccc}
\hline $\begin{array}{c}\text { No. } \\
\text { Soal }\end{array}$ & SA & SB & TK & Keterangan \\
\hline 1 & 15 & 4 & 0,63 & Sedang \\
2 & 15 & 7 & 0,73 & Mudah \\
3 & 15 & 11 & 0,87 & Mudah \\
4 & 15 & 11 & 0,87 & Mudah \\
5 & 14 & 9 & 0,77 & Mudah \\
6 & 14 & 10 & 0,80 & Mudah \\
7 & 14 & 10 & 0,80 & Mudah \\
8 & 15 & 7 & 0,73 & Mudah \\
9 & 13 & 9 & 0,73 & Mudah \\
10 & 14 & 8 & 0,73 & Mudah \\
11 & 8 & 0 & 0,27 & Sukar \\
12 & 12 & 6 & 0,60 & Sedang \\
13 & 13 & 7 & 0,67 & Sedang \\
14 & 13 & 5 & 0,60 & Sedang \\
15 & 10 & 3 & 0,43 & Sedang \\
16 & 13 & 8 & 0,70 & Sedang \\
17 & 13 & 4 & 0,57 & Sedang \\
18 & 7 & 0 & 0,23 & Sukar \\
19 & 5 & 0 & 0,17 & Sukar \\
20 & 6 & 0 & 0,20 & Sukar \\
\hline
\end{tabular}

\section{Daya Pembeda}

Daya pembeda soal (Sundayana, 2016 : 76 ) adalah kemampuan suatu soal untuk dapat membedakan antara siswa yang pandai (berkemampuan tinggi ) dan siswa yang bodoh ( berkemampuan rendah ). Untuk soal tipe objektif, peneliti menggunakan rumus serta klasifikasi berdasar tulisan Sundayana ( 2016 : 76-77 ):

$$
D P=\frac{J B_{A}-J B_{B}}{J S A}
$$

Setelah dilakukan perhitungan mengenai daya pembeda, maka peneliti sajikan pada tabel berikut:

Tabel 5. Rekapitulas Daya Pembeda Instrumen Penelitian

\begin{tabular}{lllll} 
No. Soal & SA & SB & DP & Keterangan \\
\hline
\end{tabular}

\begin{tabular}{ccccc}
\hline 1 & 15 & 4 & 0,73 & Baik sekali \\
2 & 15 & 7 & 0,53 & Baik \\
3 & 15 & 11 & 0,27 & Cukup \\
4 & 15 & 11 & 0,27 & Cukup \\
5 & 14 & 9 & 0,33 & Cukup \\
6 & 14 & 10 & 0,27 & Cukup \\
7 & 14 & 10 & 0,27 & Cukup \\
8 & 15 & 7 & 0,53 & Baik \\
9 & 13 & 9 & 0,27 & Cukup \\
10 & 14 & 8 & 0,4 & Baik \\
11 & 8 & 0 & 0,53 & Baik \\
12 & 12 & 6 & 0,4 & Baik \\
13 & 13 & 7 & 0,4 & Baik \\
14 & 13 & 5 & 0,53 & Baik \\
15 & 10 & 3 & 0,47 & Baik \\
16 & 13 & 8 & 0,33 & Cukup \\
17 & 13 & 4 & 0,6 & Baik \\
18 & 7 & 0 & 0,47 & Baik \\
19 & 5 & 0 & 0,33 & Cukup \\
20 & 6 & 0 & 0,4 & Baik \\
\hline
\end{tabular}

Dari tabel daya pembeda, terlihat bahwa daya pembeda instrumen penelitian tergolong cukup, baik, dan sangat baik, dengan jumlah soal kategori cukup sebanyak 8 butir, baik berjumlah 11 soal, dan sangat baik 1 buah.

\section{Teknik Pengumpulan Data}

Dalam penelitian kuantitatif seperti eksperimen, kegiatan analisis datanya meliputi pengumpulan data, pengolahan data, analisis data serta interpretasi data. Dalam analisis data penelitian ini, peneliti gambarkan tahapannya sebagai berikut:

\section{Pengumpulan data}

Pengumpulan data adalah salah satu kegiatan mengumpulkan data yang merupakan jawaban siswa kelompok eksperimen dan kelompok kontrol sebagai sampel terhadap soal tes baik pretest maupun posttest.

\section{Pengolahan Data}


Untuk pengolahan data dilakukan kegiatan-kegiatan sebagai berikut:

a. Proses editing, yaitu proses pengecekan jawaban pretest dan posttest kelompok eksperimen dan kontrol dengan tujuan untuk mengoreksi kesalahan dan kekurangan yang ditemukan.

b. Proses codeting, yaitu proses pemberian kode tertentu yang dapat membedakan identitas masingmasing kelompok eksperimen dan kontrol untuk semua jawaban pretes dan postes.

c. Proses tabulasi, yaitu proses penempatan data jawaban pretes dan postes ke dalam bentuk tabel.

\section{Analisis Data}

Dikarenakan penelitian ini merupakan penelitian perbandingan dua sampel yang saling bebas, maka langkah-langkah yang dilakukan dalam analisis data sebagaimana ditulis oleh Sundayana ( $2016: 142-153$ ) sebagai berikut :

a. Melakukan uji normalitas data terhadap jawaban pretest dan posttest dari kelompok eksperimen dan kontrol. Uji normalitas data ini menjadi syarat untuk menentukan jenis statistik apa yang akan dipakai dalam penganalisaan selanjutnya. Apabila hasil uji normalisasi data diketahui berdistribusi tidak normal, maka statistik non parametrik yang dapat dipergunakan, sebaliknya apabila hasilnya diketahui berdistribusi normal, maka statistik parametrik yang dapat dipergunakan ( Sundayana, 2016 : 83). Untuk pengujian apakah data berdistribusi normal atau tidak, peneliti menggunakan rumus Uji Lilliefors (Sundayana, 2016 : 83) dengan rumus :

$$
z=\frac{X-\bar{X}}{S}
$$

Jika kedua kelompok sampel yang dibandingkan berdistribusi normal, maka akan digunakan uji $\mathrm{t}$ (independent sample t test); tetapi jika salah satu atau kedua kelompok data tidak berdistribusi normal, maka akan menggunakan uji statistik non parametrik, dalam hal ini uji Mann Whitney (Sundayana, 2016: 143).

\section{b. Melakukan uji homogenitas varians}

Adapun langkah-langkah uji homogenitas dua varians (Sundayana, 2016 ; 144) sebagai berikut :

Merumuskan hipotesis nol dan alternatifnya “

Ho : Kedua varians homogen $(\mathrm{v} 1=\mathrm{v} 2)$

Ha : Kedua varians tidak homogen $(\mathrm{v} 1 \neq$ v2)

Menentukan nilai $\mathrm{F}$ hitung dengan rumus (Sundayana, $2016: 144$ )

$$
\text { Fhitung }=\frac{\text { variansbesar }=(\text { simpanganbakubesar })^{2}}{\text { varianskecil( } \text { (simpanganbakukecil })^{2}}
$$

Menentukan nilai $\mathrm{F}$ tabel dengan rumus :

$\mathrm{F}$ tabel $=\mathrm{Fa}(\mathrm{dk} \mathrm{n}$ varians besar $-1 / \mathrm{dk} \mathrm{n}$ varians kecil -1)

Kriteria uji :

Jika $\mathrm{F}$ hitung $\leq \mathrm{F}$ tabel, maka Ho diterima (Varians Homogen)

Jika kedua kelompok sampel berdistribusi normal, maka dilanjutkan dengan menguji homogenitas kedua varians dengan ketentuan :

a) Jika menghasilkan varians yang homogen, maka dilanjutkan dengan uji t. Adapun langkah-langkah uji t adalah sebagai berikut :

- Menentukan hipotesis nol dan hipotesis alkternatifnya.

- Menentukan nilai t hitung dengan rumus :

- Rumus t hitung ( Sundayana, 2016 ; 146).

- Menentukan nilai $\mathrm{t}$ tabel $=\mathrm{t} \mathrm{a}(\mathrm{dk}=$ $\mathrm{n} 1+\mathrm{n} 2-2)$

- Kriteria pengujian hipotesis : 
Gunahumas

Jurnal Kehumasan

Jika : $-\mathrm{t}$ tabel $\leq \mathrm{t}$ hitung $\leq \mathrm{t}$

tabel, maka Ho diterima.

b) Jika hasil penelitian diketahui sebaran datanya berdistribusi normal tetapi mempunyai varians yang tidak homogen, maka uji t' dapat digunakan dengan langkahlangkah sebagai berikut (Sundayana, 2016 ; 148) :

- Merumuskan hipotesis nol dan alternatifnya

- Menentukan nilai t' hitung dengan rumus :

- Rumus t'hitung (Sundayana, 2016 : 148).

- Menentukan kriteria pengujian hipotesis dengan ketentuan Ho diterima. (Sundayana, 2016 : 148).

\section{c) Melakukan}

uji

gain

\section{ternormalisasi}

Untuk mengetahui peningkatan hasil belajar siswa, maka akan digunakan gain ternormalisasi (g). Gain ternormalisasi untuk memberikan gambaran umum peningkatan hasil belajar antara sebelum dan sesudah pembelajaran. Besarnya peningkatan sebelum dan sesudah pembelajaran dihitung dengan rumus gain ternormalisasi (normalized gain) yang dikembangkan oleh Hake (Sundayana, 2016 : 151) sebagai berikut :

$$
\mathrm{g}=\frac{\text { skor postes }- \text { skor pretes }}{\text { Skor ideal }- \text { skor pretes }}
$$

Adapun interpretasi gain ternormalisasikan seperti tabel berikut

Tabel 6. Interpretasi Gain Ternormalisasikan

\begin{tabular}{cc}
\hline Nilai $\mathrm{g}$ & Interpretasi \\
\hline$-1,00 \leq \mathrm{g}<0,00$ & Terjadi \\
& penurunan \\
$\mathrm{g}=0,00$ & Tetap \\
$0,00<\mathrm{g}<0,030$ & Rendah
\end{tabular}

$0,30 \leq \mathrm{g}<0,70 \quad$ Sedang $0,70 \leq \mathrm{g} \leq 1,00 \quad$ Tinggi

d) Alat statistik yang akan digunakan peneliti adalah MS Excel dan Aplikasi Statistical Passage for Social Science (SPSS) versi 20,0 dengan pertimbangan lebih cepat dan lebih akurat sebagai prinsip pengolahan data (Santoso 2016:9). Demikian juga menurut Umar ( 2014 : 166 ) bahwa : “ Pengujian yang dilakukan secara statistik dapat dilakukan secara manual atau dukungan komputer, misalnya melalui bantuan paket komputer SPSS".

\section{HASIL PENELITIAN DAN \\ PEMBAHASAN}

\section{Hasil Penelitian}

\section{Kelas Ekperimen}

\section{a. Ketuntasan Belajar}

Pada proses pembelajaran kelas eksperimen dilakukan tes pengetahuan melalui pretest pada awal pertemuan pertama, di mana para siswa belum mengenal materi yang akan dipelajari. Lalu para siswa mengikuti proses pembelajaran dengan menggunakan model pembelajaran Mobile Learning yang berbasis android dan setelah selesai mengikuti proses pembelajaran, para siswa mengikuti tes pengetahuan melalui posttest, kemudian didapat suatu data yang akan dihitung dan dianalisis untuk dijadikan dasar dalam menarik sebuah kesimpulan dari penelitian yang telah dilakukan di kelas X OTKP 1 SMK Ngeri 14 Garut pada tahun Pelajaran 2018-2019. Dari 20 butir soal pretest dan posttest, yang diujikan terhadap 30 siswa kelas X OTKP 1 SMK Negeri 14 Garut sebagai kelas eksperimen diperoleh ratarata hasil nilai prestest dan posttest yaitu sebesar $30 \%$ dan 84,67 \%. Data rekapitulasi jawaban prestest dan 
posttest kelas ekperimen dapat dilihat pada lampiran.
Adapun persentase aspek pengetahuan kelas eskperimen dapat dilhat pada tabel dan grafik berikut:

4.1 Tabel Data Hasil Tes Pengetahuan Materi Degrees Of Comparison Kelas Eksperimen Menggunakan Mobile Learning yang Berbasis Android

\begin{tabular}{|c|c|c|c|c|c|c|}
\hline \multirow{2}{*}{ No } & \multirow{2}{*}{ Nama } & \multicolumn{2}{|c|}{ Prestest } & \multicolumn{2}{|c|}{ Posttest } & \multirow{2}{*}{ Ketuntasan } \\
\hline & & Skor & $\%$ & Skor & $\%$ & \\
\hline 1 & Cica Anisa & 8 & 40 & 18 & 90 & Tuntas \\
\hline 2 & Dede Ismi Patiyatul M & 8 & 40 & 18 & 90 & Tuntas \\
\hline 3 & Dede Nurohmah & 9 & 45 & 17 & 85 & Tuntas \\
\hline 4 & Dede Rahmawati & 8 & 40 & 16 & 80 & Tuntas \\
\hline 5 & Dila Siti Hamidah & 4 & 20 & 17 & 85 & Tuntas \\
\hline 6 & Fitri Widya N & 6 & 30 & 19 & 95 & Tuntas \\
\hline 7 & Fitri Yani & 10 & 50 & 18 & 90 & Tuntas \\
\hline 8 & Hesti Arimbi & 1 & 5 & 18 & 90 & Tuntas \\
\hline 9 & Hilda Wanti & 3 & 15 & 18 & 90 & Tuntas \\
\hline 10 & M. Hilal Hamdi & 7 & 35 & 20 & 100 & Tuntas \\
\hline 11 & Karina & 3 & 15 & 19 & 95 & Tuntas \\
\hline 12 & Kistiani & 3 & 15 & 16 & 80 & Tuntas \\
\hline 13 & Lisna Rahmawati & 4 & 20 & 18 & 90 & Tuntas \\
\hline 14 & Mira Rahmawati & 6 & 30 & 19 & 95 & Tuntas \\
\hline 15 & Nisa Nurpaidah & 5 & 25 & 18 & 90 & Tuntas \\
\hline 16 & Pipit Jamilah & 6 & 30 & 18 & 90 & Tuntas \\
\hline 17 & Pipit Pitriani & 6 & 30 & 16 & 80 & Tuntas \\
\hline 18 & Rahma Albar Dayanti & 7 & 35 & 18 & 90 & Tuntas \\
\hline 19 & Rani Yulianti & 9 & 45 & 18 & 90 & Tuntas \\
\hline 20 & Rinrin Sawitri & 2 & 10 & 18 & 90 & Tuntas \\
\hline 21 & Rina & 4 & 20 & 5 & 25 & $\begin{array}{l}\text { Belum } \\
\text { Tuntas }\end{array}$ \\
\hline 22 & Rosdiana Alpiani & 10 & 50 & 18 & 90 & Tuntas \\
\hline 23 & Silvi Pujianti & 6 & 30 & 19 & 95 & Tuntas \\
\hline 24 & Sinly Fadilah & 6 & 30 & 18 & 90 & Tuntas \\
\hline 25 & Siska Dewi Siti Afifah & 9 & 45 & 18 & 90 & Tuntas \\
\hline 26 & Siti Sopiah & 4 & 20 & 14 & 70 & $\begin{array}{l}\text { Belum } \\
\text { Tuntas }\end{array}$ \\
\hline 27 & Sri Rahayu & 9 & 45 & 19 & 95 & Tuntas \\
\hline 28 & Yaris Pratama & 4 & 20 & 16 & 80 & Tuntas \\
\hline 29 & Santi Pebrianti & 5 & 25 & 6 & 30 & $\begin{array}{l}\text { Belum } \\
\text { Tuntas }\end{array}$ \\
\hline 30 & Gina Anggi & 8 & 40 & 18 & 90 & Tuntas \\
\hline & Rata-rata & 6 & 30 & 16,93 & 84,67 & \\
\hline
\end{tabular}

Dari Tabel 4.1 terlihat bahwa siswa yang mengikuti tes ada yang tuntas dan ada juga yang belum tuntas. Dari hal tersebut, kemudian peneliti sajikan rekapitulasi ketuntasan hasil belajar sebagai berikut:
Tabel 4.2 Rekapitulasi Ketuntasan Kelas Eksperimen

$\begin{array}{lll}\text { Ketuntasan } & \mathrm{f}_{\mathrm{i}} \quad \text { Persen }\end{array}$


Gunahumas

Jurnal Kehumasan

\begin{tabular}{ccc}
\hline Tuntas & 27 & 90 \\
Belum Tuntas & 3 & 10 \\
Jumlah & 30 & 100 \\
\hline
\end{tabular}

Berdasarkan Tabel 4.2 di atas terlihat bahwa siswa yang mengikuti proses pembelajaran pada kelas eksprimen dengan menggunakan model pembelajaran mobile learning yang berbasis android dan dilakukan posttest untuk melihat hasil nilai yang dicapai, siswa yang mendapatkan nilai di atas KKM mencapai $90 \%$ dan yang mendapatkan nilai di bawah KKM mencapai $10 \%$. Artinya siswa yang tuntas dalam mengikuti proses pembelajaran Bahasa Inggris: Degrees of Comparison mencapai $90 \%$ dan yang belum tuntas mencapai $10 \%$. Jadi proses pembelajaran ini mencapai ketuntasan.

Dengan adanya penjelasan di atas maka peneliti dapat menyimpulkan bahwa model pembelajaran mobile learning yang berbasis android dipandang cocok

digunakan pada pembelajaran Bahasa InggrisL Degrees of Comparison di kelas X OTKP 1 SMKN 14 Garut.

\section{Peningkatan Hasil Belajar}

Setelah peneliti selesai melakukan proses pretest, proses pembelajaran dengan menggunakan model pembelajaran mobile learning yang berbasis android dan diakhiri posttest dalam aspek pengetahuan kepada para siswa pada kelas eksperimen dengan perolehan data yang terdapat pada Tabel 4.1 dan Tabel 4.2. di atas, maka dapat dihitung peningkatan hasil belajar siswa dengan menggunakan gain ternormalisasi. Adapun rumus gain ternormalisasi (GT) adalah:

$$
\text { GT }=\frac{\text { Skor Postes }- \text { Skor Pretes }}{\text { Skor Ideal }- \text { skor Pretes }}
$$

(Sundayana, 2014:150)

Setelah dilakukan perhitungan diperoleh data hasil peningkatan hasil belajar sebagai berikut:

Tabel 4.2.2 Data Hasil Tes Pengetahuan Materi Degrees Of Comparison Kelas Eksperimen Menggunakan Mobile Learning yang Berbasis Android

\begin{tabular}{rlcccc}
\hline No & \multicolumn{1}{c}{ Nama } & Prestest & Posttest & Gain & Interpretasi \\
\hline 1 & Cica Anisa & 8 & 18 & 0.83 & Tinggi \\
2 & Dede Ismi Patiyatul M & 8 & 18 & 0.83 & Tinggi \\
3 & Dede Nurohmah & 9 & 17 & 0.73 & Tinggi \\
4 & Dede Rahmawati & 8 & 16 & 0.67 & Sedang \\
5 & Dila Siti Hamidah & 4 & 17 & 0.81 & Tinggi \\
6 & Fitri Widya N & 6 & 19 & 0.93 & Tinggi \\
7 & Fitri Yani & 10 & 18 & 0.80 & Tinggi \\
8 & Hesti Arimbi & 1 & 18 & 0.89 & Tinggi \\
9 & Hilda Wanti & 3 & 18 & 0.88 & Tinggi \\
10 & M. Hilal Hamdi & 7 & 20 & 1.00 & Tinggi \\
11 & Karina & 3 & 19 & 0.94 & Tinggi \\
12 & Kistiani & 3 & 16 & 0.76 & Tinggi \\
13 & Lisna Rahmawati & 4 & 18 & 0.88 & Tinggi \\
14 & Mira Rahmawati & 6 & 19 & 0.93 & Tinggi \\
15 & Nisa Nurpaidah & 5 & 18 & 0.87 & Tinggi \\
16 & Pipit Jamilah & 6 & 18 & 0.86 & Tinggi \\
17 & Pipit Pitriani & 6 & 16 & 0.71 & Tinggi \\
18 & Rahma Albar Dayanti & 7 & 18 & 0.85 & Tinggi \\
\hline
\end{tabular}


Linda Setiawatilipip Purosad ${ }^{2}$, Deni Darmawan/ Implementasi Model Pembelajaran Mobile Learning Berbasis Android dalam Meningkatkan Prestasi Belajar Siswa Pada Pembelajaran Bahasa Inggris: Degrees of Comparison

\begin{tabular}{rlcccc}
\hline No & \multicolumn{1}{c}{ Nama } & Prestest & Posttest & Gain & Interpretasi \\
\hline 19 & Rani Yulianti & 9 & 18 & 0.82 & Tinggi \\
20 & Rinrin Sawitri & 2 & 18 & 0.89 & Tinggi \\
21 & Rina & 4 & 5 & 0.06 & Rendah \\
22 & Rosdiana Alpiani & 10 & 18 & 0.80 & Tinggi \\
23 & Silvi Pujianti & 6 & 19 & 0.93 & Tinggi \\
24 & Sinly Fadilah & 6 & 18 & 0.86 & Tinggi \\
25 & Siska Dewi Siti Afifah & 9 & 18 & 0.82 & Tinggi \\
26 & Siti Sopiah & 4 & 14 & 0.63 & Sedang \\
27 & Sri Rahayu & 9 & 19 & 0.91 & Tinggi \\
28 & Yaris Pratama & 4 & 16 & 0.75 & Tinggi \\
29 & Santi Pebrianti & 5 & 6 & 0.07 & Rendah \\
30 & Gina Anggi & 8 & 18 & 0.83 & Tinggi \\
& Rata-rata & 6.00 & 16.93 & 0.78 & Tinggi \\
\hline
\end{tabular}

Dengan adanya peningkatan hasil belajar ini membuktikan bahwa proses pembelajaran dengan menggunakan model pembelajaran mobile learning yang berbasis android yang dilakukan oleh peneliti telah berhasil meningkatkan prestasi belajar siswa di kelas X OTKP 1 SMKN 14 Garut.

\section{Kelas Kontrol \\ Ketuntasan Belajar}

Pada proses pembelajaran kelas kontrol pun dilakukan tes pengetahuan melalui pretest pada awal pertemuan pertama seperti yang dilakukan pada kelas eskperimen, di mana para siswa belum mengenal materi yang akan dipelajari. Lalu para siswa mengikuti proses pembelajaran tanpa menggunakan model pembelajaran Mobile Learning yang berbasis android tapi menggunakan model pembelajaran konvensional dan setelah selesai mengikuti proses pembelajaran, para siswa mengikuti tes pengetahuan melalui posttest, kemudian didapat suatu data yang akan dihitung dan dianalisis untuk dijadikan dasar dalam menarik sebuah kesimpulan dari penelitian yang telah dilakukan di kela X OTKP 2 SMK Negeri 14 Garut pada tahun Pelajaran 2018-2019. Dari 20 butir soal pretest dan posttest, yang diujikan terhadap 30 siswa kelas X OTKP 1 SMK Negeri 14 Garut sebagai kelas kontrol diperoleh rata-rata hasil nilai prestest dan posttest yaitu sebesar $29,33 \%$ dan $59,17 \%$. Data rekapitulasi jawaban prestest dan posttest kelas kontrol dapat dilihat pada lampiran.

Adapun persentase aspek pengetahuan kelas kontrol dapat dilhat pada tabel dan grafik berikut:

Tabel 4.3 Data Hasil Tes Pengetahuan Materi Degrees Of Comparison Kelas Kontrol Tanpa Menggunakan Mobile Learning Berbasis Android

\begin{tabular}{clccccl}
\hline \multirow{2}{*}{ NO } & \multirow{2}{*}{ NAMA } & \multicolumn{2}{c}{ PRETEST } & \multicolumn{2}{c}{ POSTTEST } & \multirow{2}{*}{ Ketuntasan } \\
\cline { 3 - 6 } & & Skor & \% & Skor & \% & \\
\hline 1 & Ai rini P & 4 & 20 & 5 & 25 & Belum Tuntas \\
2 & Ai Rostita & 6 & 30 & 17 & 85 & Tuntas \\
3 & Ai Safitri & 9 & 45 & 11 & 55 & Belum Tuntas \\
4 & Ani Nuraeni & 3 & 15 & 11 & 55 & Belum Tuntas \\
5 & Arvi Putri R & 8 & 40 & 14 & 70 & Belum Tuntas \\
6 & Bisma Abdul Z & 4 & 20 & 13 & 65 & Belum Tuntas \\
7 & Daris Fikri F & 4 & 20 & 13 & 65 & Belum Tuntas \\
\hline
\end{tabular}




\begin{tabular}{clccccl}
\hline 8 & Dewi Puspita & 6 & 30 & 17 & 85 & Tuntas \\
9 & Henti Ha & 6 & 30 & 13 & 65 & Belum Tuntas \\
10 & Mega N.J. & 5 & 25 & 12 & 60 & Belum Tuntas \\
11 & Mutia Husna & 9 & 45 & 13 & 65 & Belum Tuntas \\
12 & Nadia Putri L & 8 & 40 & 11 & 55 & Belum Tuntas \\
13 & Nenden Siti Ha & 8 & 40 & 9 & 45 & Belum Tuntas \\
14 & neneng Sinta A & 5 & 25 & 9 & 45 & Belum Tuntas \\
15 & Neng Naima & 5 & 25 & 9 & 45 & Belum Tuntas \\
16 & Neng Rahmi M & 4 & 20 & 13 & 65 & Belum Tuntas \\
17 & Neng Seltri R.P. & 9 & 45 & 18 & 90 & Tuntas \\
18 & Neng Winarti & 3 & 15 & 7 & 35 & Belum Tuntas \\
19 & Novi Andasari & 8 & 40 & 9 & 45 & Belum Tuntas \\
20 & Nuri Santika & 6 & 30 & 10 & 50 & Belum Tuntas \\
21 & Sani Saniyah & 9 & 45 & 18 & 90 & Tuntas \\
22 & Santi Novianti & 7 & 35 & 18 & 90 & Tuntas \\
23 & Sifa Faoziah & 6 & 30 & 14 & 70 & Belum Tuntas \\
24 & Sivi Novianti & 6 & 30 & 11 & 55 & Belum Tuntas \\
25 & Sindi Melani P & 4 & 20 & 13 & 65 & Belum Tuntas \\
26 & Sinta Apriliani & 9 & 45 & 10 & 50 & Belum Tuntas \\
27 & Siti Nurhasanah & 5 & 25 & 7 & 35 & Belum Tuntas \\
28 & Sri Nabila W & 3 & 15 & 7 & 35 & Belum Tuntas \\
29 & Via Aprilia & 2 & 10 & 9 & 45 & Belum Tuntas \\
30 & Yanti Herdiani & 5 & 25 & 14 & 70 & Belum Tuntas \\
& Rata-Rata & 5.87 & 29.33 & 11.83 & 59.17 & \\
\hline
\end{tabular}

Dari Tabel 4.3 terlihat bahwa siswa yang mengikuti tes ada yang tuntas dan ada juga yang belum tuntas. Dari hal tersebut, kemudian peneliti sajikan rekapitulasi ketuntasan hasil belajar sebagai berikut:

Tabel 4.4 Rekapitulasi Ketuntasan Kelas Kontrol

\begin{tabular}{ccc}
\hline Ketuntasan & fi & Persen \\
\hline Tuntas & 5 & 17 \\
Belum Tuntas & 25 & 83 \\
\hline Jumlah & 30 & 100 \\
\hline
\end{tabular}

\section{Peningkatan Hasil Belajar}

1. Proses belajar mengajar dengan menggunakan model pembelajaran mobile learning telah mampu meningkatkan lebih maksimal dalam pemanfaatan handphone dalam proses belajar siswa kelas X OTKP 1 SMKN 14 Garut.

2. Penggunaan model pembelajaran mobile learning tersebut telah mampu meningkatkan prestasi belajar siswa kelas X OTKP 1 SMKN 14 Garut.

3. Penggunaan model pembelajaran mobile learning tersebut telah ada perbedaan prestasi belajar yang signifikan antara kelas X OTKP 1 dan kelas X OTKP 2 SMKN 14 Garut.

\section{SIMPULAN}

Dari hasil pembahasana pada Bab IV, maka peneliti menarik kesimpulan bahwa:

1. Pemanfaatan handphone / smartphone yang berfitur android dimiliki oleh 
setiap siswa pada proses pembelajaran Bahasa Inggris dengan menggunakan model pembelajaran mobile learning telah mampu meningkatkan lebih maksimal dalam proses belajar siswa di kelas X OTKP 1 SMKN 14 Garut.

2. Penggunaan model pembelajaran mobile learning pada pembelajaran Bahasa Inggris dalam pokok bahasan degrees of comparison telah mampu meningkatkan prestasi belajar siswa kelas X OTKP 1 SMKN 14 Garut

3. Penggunaan model pembelajaran mobile learning berbasis android pada pembelajaran Bahasa Inggris dengan pokok bahasan degrees of comparison di kelas X OTKP 1 menjadi sangat berbeda prestasi belajar yang signifikan dengan prestasi kelas $\mathrm{X}$ OTKP 2 yang menggunakan model pembelajaran konvensional.

\section{Rekomendasi}

Berdasarkan simpulan di atas, peneliti memberikan rekomendasi:

1. Bagi sekolah yang memiliki sarana dan prasarana yang memadai dan cukup baik dibidang teknologi informasi dan komunikasi, merekomendasikan untuk dapat menerapkan media pembelajaran yang berbetuk mobile learning berbasis android dalam kegiatan belajar mengajar pada setiap mata pelajaran.

2. Bagi pengajar, peneliti merekormendasikan untuk dapat menyusun dan mengembangkan mobile learning yang berbasis android agar dapat meningkatkan pengetahuan dan keterampilan siswa dan mebuat proses pembelajaran lebih menyenangkan. Hal ini disebabkan mobile learning yang berbasis android membantu pengajar dalam menjelaskan materi kepada siswa. Oleh karena itu, pengajar diharapkan lebih kreatif dan aktif dalam pelaksanaan pembelajaran yang meliputi perencanaan, pembuatan desain pembelajaran, media yang digunakan sampai evaluasi sehingga berimpilkasi positif pada belajar siswa

3. Bagi peneliti, peneliti merekomendasikan agar dapat mengembangkan dan membenahi penyusunan mobile learning yang berbasis android agar dapat lebih menigkatkan kualitas media yang lebih baik.

\section{DAFTAR PUSTAKA}

Abdulhak, I. dkk. (2013). Teknologi Pendidikan. Bandung: Remaja Rosdakarya.

Darmawan, D. (2013). Metode penelitian Kuantitaif. Bandung: Rosdakarya

Darmawan, D. (2016). Pengembangan ELearning. Bandung: Rosdakarya

Darmawan, D. (2011). Teknologi Pembelajaran. Bandung: Remaja Rosdakarya.

Depdikdas, (2003). Undang-Undang Sikdisnas No. 20 tahun 2003. Jakarta: Sinar Grafika

Sundayana, R. (2015). Statistik Penelitian Pendidikan. Bandung: Alfabeta.

Safaat N, (2012). Pemograman Apilkasi Mobile Smartphone dan Tablet PC Berbasis Android. Bandung: Informatika Bandung

Sugiyono. (2016). Metode Penelitian Pendidikan. Bandung: Alfabeta

Surya, M. (2015). Psikologi Guru Konsep dan Aplikasi. Bandung: Alfabeta.

Wahyudin. (2013). Statistika Terapan. Bandung: Penerbit Mandiri 


\section{Lampiran}

\begin{tabular}{|c|c|c|c|c|c|}
\hline No & Variabel & Konsep Variabel & Dimensi & Indikator & Skala \\
\hline \multirow[t]{11}{*}{1} & \multirow{11}{*}{$\begin{array}{l}\text { Variabel X } \\
\text { Mobile } \\
\text { Lerning } \\
\text { sebagai } \\
\text { variabel } \\
\text { bebas }(X)\end{array}$} & \multirow{11}{*}{$\begin{array}{l}\text { Mobile learning ( } \mathrm{m} \text { - } \\
\text { learning) adalah suatu } \\
\text { pendekatan } \\
\text { pembelajaran yang } \\
\text { melinatakan device } \\
\text { (perangkat) bergeraka } \\
\text { seperti telepin genggam, } \\
\text { PDA, laptop dan tablet } \\
\text { PC, di mana pembelajar } \\
\text { dapat mengakses materi, } \\
\text { arahan dan aplikasi yang } \\
\text { berkaitan dengan } \\
\text { pelajaran tanpa dibatasi } \\
\text { oleh ruang dan waktu, di } \\
\text { mana pun, kapan pun } \\
\text { mereka berada } \\
\text { (Darmawan 2015:15) }\end{array}$} & \multirow[t]{3}{*}{$\begin{array}{l}\text { Multimedia } \\
\text { inreraktif }\end{array}$} & $\begin{array}{ll}- & \text { Topik } \\
& \text { pelajaran }\end{array}$ & \multirow{11}{*}{ Ordinal } \\
\hline & & & & - $\quad$ Menarik & \\
\hline & & & & 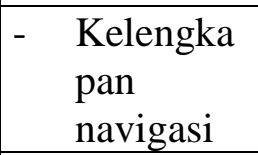 & \\
\hline & & & \multirow[t]{4}{*}{ Respon siswa } & \begin{tabular}{|ll}
- & Kebermak \\
& naan \\
\end{tabular} & \\
\hline & & & & $\begin{array}{|ll|}\text { - } & \text { Umpan } \\
\text { balik }\end{array}$ & \\
\hline & & & & $\begin{array}{ll}- & \text { Kemandir } \\
& \text { ian } \\
\end{array}$ & \\
\hline & & & & 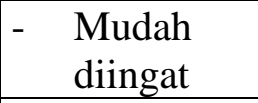 & \\
\hline & & & \multirow{4}{*}{$\begin{array}{l}\text { Alat } \\
\text { pengontrol }\end{array}$} & - $\quad$ Responsif & \\
\hline & & & & $\begin{array}{ll}- & \text { Relevansi } \\
\end{array}$ & \\
\hline & & & & - $\quad$ Bermakna & \\
\hline & & & & - $\quad$ Jelas & \\
\hline \multirow[t]{10}{*}{2} & \multirow{10}{*}{$\begin{array}{l}\text { Variabel Y1 } \\
\text { Pengetahuan } \\
\text { Degress of } \\
\text { Comparison }\end{array}$} & \multirow{10}{*}{ 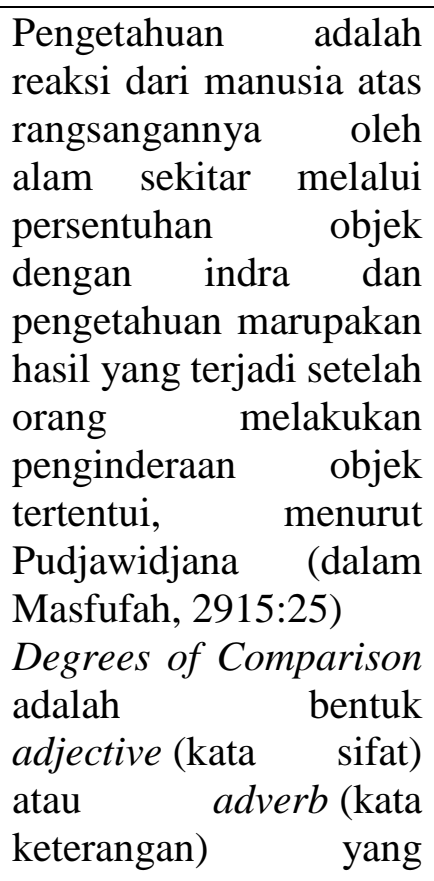 } & \multirow[t]{6}{*}{ Kognitif } & $\begin{array}{l}\text { C1 } \\
\text { (Pengetahuan } \\
\text { ) }\end{array}$ & \multirow{10}{*}{ Interval } \\
\hline & & & & $\begin{array}{l}\text { C2 ( } \\
\text { Pemahaman) }\end{array}$ & \\
\hline & & & & $\begin{array}{l}\text { C3 ( } \\
\text { Aplikasi) }\end{array}$ & \\
\hline & & & & $\begin{array}{l}\text { C3 ( } \\
\text { Analisis) }\end{array}$ & \\
\hline & & & & C5 (Evaluasi) & \\
\hline & & & & C6 ( Kreasi) & \\
\hline & & & \multirow[t]{4}{*}{ Afektif } & $\begin{array}{l}\text { A1 } \\
\text { (Menerima) }\end{array}$ & \\
\hline & & & & $\begin{array}{l}\text { A2 ( } \\
\text { Menanggapi) }\end{array}$ & \\
\hline & & & & A3 ( Menilai) & \\
\hline & & & & $\begin{array}{l}\text { A4 ( } \\
\text { Mengelola) }\end{array}$ & \\
\hline
\end{tabular}


Linda Setiawati ${ }^{1}$ Apip Purosad ${ }^{2}$, Deni Darmawan³/ Implementasi Model Pembelajaran Mobile Learning Berbasis Android dalam Meningkatkan Prestasi Belajar Siswa Pada Pembelajaran Bahasa Inggris: Degrees of Comparison

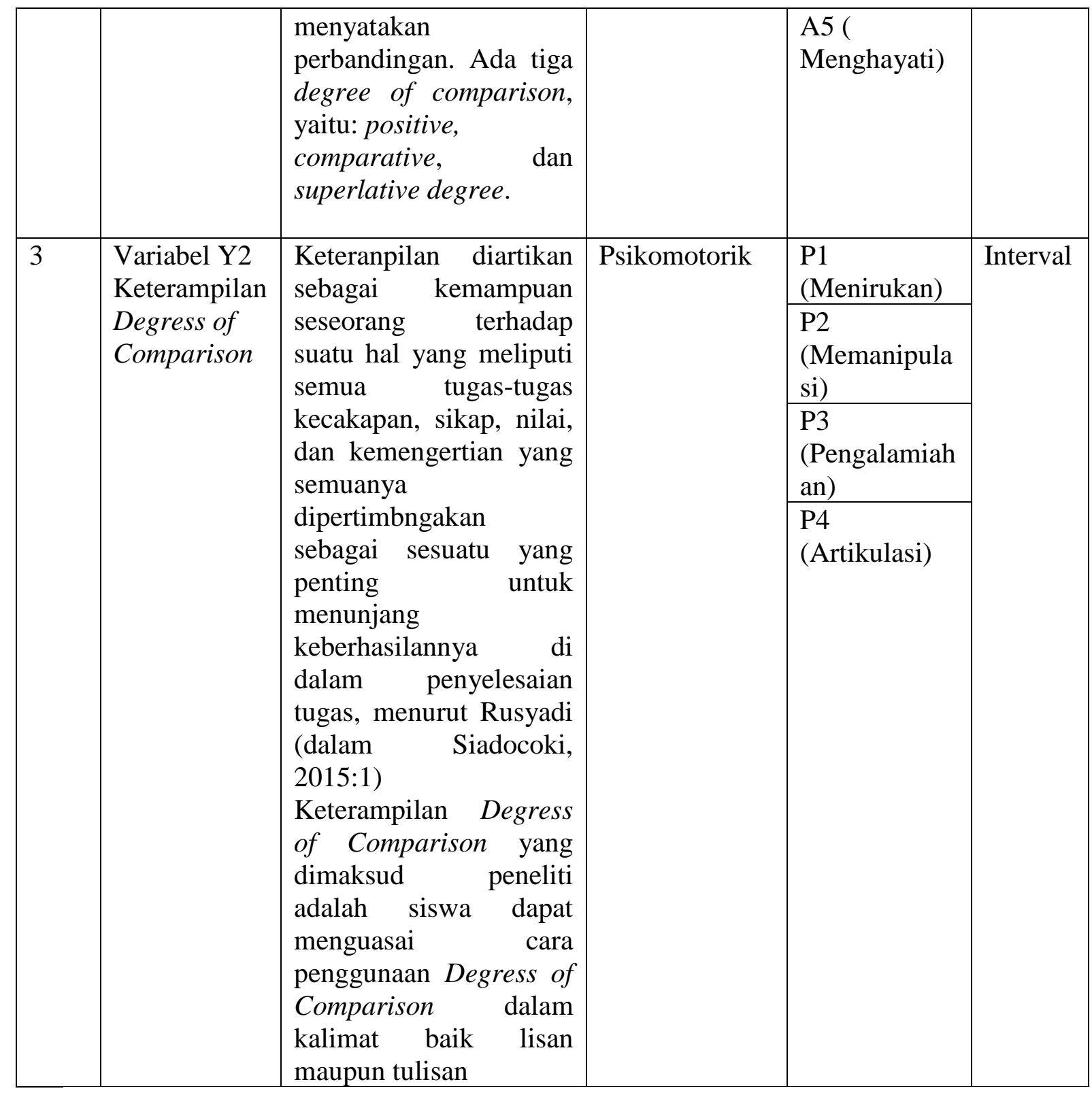

